\title{
Psychological Challenges Facing Orphaned Children and Caregivers: A Case of Ubungo Institutionalized Centers in Dar es Salaam, Tanzania
}

\author{
Theophil Christopher ${ }^{1}$ and Mary A. Mosha, $\mathrm{PhD}^{2^{*}}$ \\ ${ }^{1}$ Jordan University, Tanzania \\ ${ }^{2}$ Kampala International University, Tanzania \\ *Corresponding Mail: dr.marymosha@gmail.com
}

\begin{abstract}
The purpose of the study was to establish psychological challenges facing orphaned children and caregivers residing in six institutionalized institutions located at Ubungo District in Dar es Salaam. The study involved 67 participants who were selected through purposive sampling technique. They included twelve caregivers, six Directors, one Social Welfare Officer and 48 children. The study applied the descriptive research design. Data were collected using in-depth interviews and non-participant observation. Data were sorted and coded based on themes and presented according to the research questions through the thematic approach. Results indicated that orphan children were faced with stigma, discrimination, bullying, physical punishment, anxiety, poor attachment and isolation. To some extent, the challenges were caused by grief and lack of counseling knowledge and skills from the caregivers. Additionally, care givers had limited freedom to punish/discipline children with misbehaviors. Therefore, the study recommends counseling training for caregivers in order to minimize children psychological complexities and misbehaviors as well as furnishing of life skills training for orphans.
\end{abstract}

Keywords: Depression, emotions, accommodation, protection, training, development.

\section{Introduction}

An orphan is a child who has lost his mother, father or both parents to any cause (UNICEF, 2008). The death of parents to the child is an upsetting event (Report on World's Orphan, 2014). In most cases, orphaned children are likely to experience anxiety, rejection, aggression, idealization and guilt. The parents' death affects the living system that children had been undergoing before (Mchau, 2010). This study considers orphan children as those whose safety; well-being and development are threatened by lack of psychological support.

Orphans are likely to express psychological difficulties compared to their peers. The psychological difficulties include depression, anger, anxiety and feelings of sadness (UNICEF, 2018). These problems are brought due to failure to deal with their sense of loss (Ntuli, Mogkatle and Madiba 2020). It is argued that, loss of parents often compromises children's psychosocial well-being whereby some orphans are taken to extended families or orphanage centers or looked after by caregivers who may be unskilled or unwilling to assume the role (Davids, Nkomo, Mfekane, Skinner and Ratele, 2006).

An estimated 153 million children worldwide are orphans and 10,000 children become orphans every day out of which 15.1 million lost both parents (UNICEF, 2020). Among those orphans, 61 million are in Asia, 52 million are in Africa (among them, 45 million are in Sub-Saharan Africa), 10 million are in Latin America as well as the Caribbean and 7.3 million are in Eastern Europe and Central Asia. Similarly, it is estimated that about 2.6 million children in Tanzania are orphaned due to Human Immunodeficiency Virus (HIV) and have Acquired Immune Deficiency Syndrome (AIDS) (Vedasto, 2015; Makuu, 2019). The adverse of the AIDS epidemic are most severely in some of the world's poorest countries in Sub-Saharan Africa, where one of its consequences has been an upsurge in the number of orphaned children (UNAIDS, 2010).

UNICEF (1997) reported that children exposed to war were forced to leave their homes because of 
armed conflict in Central and Eastern Europe. Thousands of the children were killed in the region and millions more suffered severe hardship, including trauma of the direct experience of war. For instance, Huynh et al. (2019) reported that leaders at global level and national level are struggling to find the solution on caring the estimated 140 million orphaned children worldwide.

A child requires parental love, care, and protection in the early stages of development because it is in this environment of the child when it is critical in determining how that child develops. Orphans need living environments that make them secured and promote their psychological well-being. Unfortunately, not all children get the mentioned requirements. It is from this point of view the world come to have orphans. For instance, Kaur, Vinnakota and Manasa (2018) found that children who are deprived of the parental care and a secure family environment often become vulnerable to the most of psychological problems and psychiatric disorders. These children are then usually reared in institutional homes set up by the government or private agencies, which provide some semblance of order into their lives. In these homes, the problem of overcrowding, inadequate personal attention, poor academic environment and frequent moves may affect the psychological health of the children.

Orphans have been supported by extended families including close relatives and neighbors. UNICEF (2015) holds that majority of the orphaned children continue to survive depending on surviving parent or family members. Currently, the number of orphans has been increasing beyond the capacity of the families and society (Ministry of Health and Social Welfare, 2009; UNICEF, 2012). In tackling these challenges, the government and other stakeholders including non-governmental institutions and religious organizations are assisting in different ways through establishment of institutions that provide basic care, support and protection to orphaned children (Ministry of Health and Social Welfare, 2009). Though quality care, support and protection have been provided to the orphaned children, the service providers lack common guidelines for provision of services. Much focus is on provision of material support like food, shelter, clothes and health services with little efforts to psychological support (Huynh, et al. 2019).

In most of the African countries, orphaned and vulnerable children fall in the category of the disadvantaged group (UNAIDS, 2010). Children in orphaned residents face many difficulties including poverty, poor physical health, attachment disorders, inadequate social skills and mental health difficulties. Added to this is the loss of one or both parents, which is difficult for the children. It makes them more vulnerable to psychological problems and the effects may not manifest until years afterwards (Atwine et al. 2005). Orphans and vulnerable children are subjected to multiple ongoing stressful and traumatic life events such as abuse, neglect, parental loss, sexual abuse among others (Murray et al. 2013).

Tanzania, like any other country in Sub-Saharan region is faced with challenges of having orphans and vulnerable children Even though the government is concerned with child care and protection. One among factors that influence children to become orphans is HIV/AIDS in families. The situation of orphans in Tanzania is exacerbated by poverty since parents or caretakers from the extended families do not generate adequate incomes for survival. They lack necessary resources to ensure their sustainable well-being. It is argued that Tanzanian children are struggling in terms of care, security and protection. Orphaned and vulnerable children have been pushed into critical discrimination, stigmatization, abuse and general neglects (Makuu, 2019).

The number of orphans in Tanzania exceeds the capacity of the extended family and the available orphanages to take care. Generally, the orphans' situation in the orphanages is seriously challenging. Statistics reveals that 18 percent of orphans live with mothers only, 6 percent live with their fathers only while 16 percent do not live with any of the biological parents (Mdamu, 2017).

It is estimated that Tanzania has more than 140 orphanage centres (Majaliwa, 2020). Among the centers, 40 (28.6\%) are in Dar es Salaam (Makuu, 2019). Most of these centers are run by religious institutions and Non-Governmental Organizations. However, there has been an argument that the interventions towards orphans in Tanzania have not achieved their intended objectives. Reasons to substantiate that status is that majority of them are still retained in residential or institutional care and other children are living and spending their lives on the streets (Mukuu, 2017).

Tanzania has taken various measures in response to the problem of orphans. Some measures include ratification of the international convection on the 
Rights of the Child (1989) and ratification of the African Charter (1990). Another measure is formulation of the policy on Child Development (1996-2008) and making a situational analysis of orphan children in six districts. Other efforts include introduction of the Regional Psychosocial Support Initiatives (REPSSI) in 2005, Development of the National Guideline for Institutional care and Support to the most vulnerable children (2007), National Costed Plan of Action for the Most Vulnerable Children (2007-2010) and Enactment of the Law of the Child Act Number 21 of 2009. Despite the efforts by the government of Tanzania to intervene the psychosocial well-being of the orphans, very little has been done to solve the problem.

In Tanzania, a child at risk is referred to social workers or the police. The police interview the child, investigate and if necessary ensure that medical examination is done and then take the child to a safe place. Then the police write a social investigation report. If the Social Welfare Officer determines that the child is at high risk, the officer applies to the court a care order and then the Social Welfare Officer refers the child to an appropriate care center (children homes) (Brizay, 2008). The homes are established by law through the Children Homes (regulations) Act of 2012. Establishment of orphanage centers has been in response to the National Child Development Policy of 1996, which emphasizes on establishment of centers and provision of necessary needs for the needy people. The main intention is to protect and safeguard the welfare of the orphans.

There is an increasing number of orphans in Tanzania. Statistics have influenced on establishment of different institutions to protect the well-being of the orphaned children. Most of the institutions are owned by government agencies, non-governmental organizations, private sectors, civil societies and religious-based organizations (Makuu, 2017). The intention of institutions is to provide care and support to children. However, it has been pointed out that most of the institutions perform their functions under scarce resources [(capital and human resources) Caserta, 2017)]. Consequently, lack of psychological support among orphaned children would likely lead to development of emotional and behavioral problems such as low self-esteem, depression, stress, anxiety and traumatic infections. For example, Msoka and Holroyd (2018) found that in Tanzania, orphaned children experience various psychological challenges which are not addressed by empirical studies. In addition, Losioki (2020) found that family and orphanage homes experienced psychological challenges. This means that there is minimal evidence which explores challenges facing orphaned children in institutionalized care centers. Therefore, this study investigated the psychological factors affecting orphaned children and caregivers in Ubungo Municipality that is located in Dar es Salaam City, Tanzania.

The objective of the study was to examine psychological challenges facing orphaned children and caregivers residing in the institutionalized centers at Ubungo Municipality. The Municipality has 25 best orphanage centers but little research has been done in the centers concerning the topic. For instance, a recent study by Ismail (2020) focused on the increase of street children in Tanzania Mainland but did not address psychological challenges facing the orphaned children and caregivers. This study therefore, sought to answer the following research questions:

1. What are the psychological challenges facing orphaned children in the orphanage institutionalized centers?

2. What are the challenges facing caregivers in the orphanage institutionalized centers?

3. What are the ways to improve orphans wellbeing?

\section{Theoretical Perspective}

The study based on psychodynamic and attachment theory developed by Bowlby (1969). Bowlby was the first attachment theorist, describing attachment as a "lasting psychological connectedness between human beings. Bowlby was interested in understanding the separation anxiety and distress that children experience when separated from their primary caregivers. However, some of the earliest behavioral theories suggested that attachment was simply a learned behavior. These theories proposed that attachment was merely the result of the feeding relationship between the child and the caregiver because as the caregiver feeds the child and provides nourishment, the child becomes attached but Bowlby urged that children are born with innate drive to form attachment with caregivers.

What Bowlby observed is that feedings did not diminish the anxiety experienced by children when they were separated from their primary 
caregivers. Instead, he found that attachment was characterized by clear behavioral and motivation patterns. Thus, when children are frightened, they will seek proximity from their primary caregiver in order to receive both comfort and care. According to Bowlby, the earliest bonds formed by children with their caregivers have a tremendous impact that continues throughout life. He suggested that attachment serves to keep the infant close to the mother, thus improving the child's chances of survival. Therefore, the central theme of attachment theory is that primary caregivers who are available and responsive to an infant's needs allow the child to develop a sense of security. The infant knows that the caregiver is dependable, which creates a secure base for the child to then explore the world.

The attachment theory reveals that orphans may face certain challenges as they stay in temporal homes. In this study, people who took care of orphans in the institutions were not primary caregivers. In this case, one cannot expect the orphans to have original attachment to the caregivers as it should be in the original mothers. In that case, orphan children face psychological challenges because it is not easy for them to cope with new environment and attach to new people who did not raise them. It is from this point of view that the attachment theory is relevant to this study.

\section{Review of Related Literature}

Orphan hood is time which involves many psychological and emotional problems. Lack of selfdetermination and inability to take decisions puts orphans at risks of anxiety (Sharif and Haider, 2020). Pillay (2016) asserts that children become orphans due to health issues like HIV/AIDS and poverty where parents fail to support the children thereby become street children and experience child abuse cases including neglect, discrimination and domestic violence. For instance, Daniel and Rukundo (2016) found that orphans who joined the institutionalized centers were very young. When they grow up, they get to know that caregivers are not their biological parents and they want to get the truth. Some of them seem difficult to call any of their caregivers as mothers or fathers.

The problem of being an orphan is not a new phenomenon. It existed even during the communalism era where orphans were taken care of, protected and supported by close relatives. Nowadays, the problem is highly pronounced due to the increase in number of orphans due to HIV/AIDS and other factors. Much attention has been paid at the national and international levels where international agencies, Non-Governmental Organizations and religious institutions are taking the responsibility of caring, supporting and protecting orphans including vulnerable children (Ntuli et al., 2020).

\section{Factors leading to orphans}

As mentioned in the introductory part, poverty and HIV/AIDS are key factors which result to orphans and vulnerable children. Due to poverty, they become child laborers and street children. It is estimated that half of the world's population lives on less than 2.5 United States dollars (US\$) per day and about 1.3 billion people are said to live in miserable poverty with less than 1.25 US\$. Many orphaned children are abandoned by parents or caregivers not due to lack of love but due to lack of resources to care for their basic needs (World Bank, 2018).

Other factors like civil wars, terrorism, natural calamities and other diseases such as Ebola and Malaria contribute to the increasing number of orphans in Sub-Saharan Africa (UNICEF, 2006; Christian Alliance for Orphans, 2014). All these factors have strengthened susceptibility of orphans in such a way that children are struggling for security, care and protection (Makuu, 2017). Due to these factors, orphans and vulnerable children have been pushed into critical discrimination, stigmatization, exploitation, abuse and general neglect from society (Save the Children, 2013).

\section{Care Practices and Support to Orphanage Centers}

Management is required at the centers for planning, organizing, leading and controlling affairs of the orphanage centers. For that matter, managers and caregivers are supposed to have management skills so as to ensure proper coordination and leading. Most centers have caregivers who take care of the orphans at the centers. They are the more influential on the children's life ways because they interact daily with the orphan children (Ismail, Hindawi, Awamleh \& Alawamleh, 2018). Research by Mears, Singletary and Rogers (2011) found that child care centers provide support to orphans in the following areas: psychosocial as well as material support, health care, education support and protection of children from gender discrimination, abuse and labor exploitation. However, the overall 
living conditions in most of the surveyed orphanages were poor and health-care was inadequate in some orphanages. Besides, there were indications that access to food was limited and quality of care was substandard due to limited financial resources, lack of supervision and minimal awareness of children's development issues. Furthermore, Government-owned and NonGovernmental Organizations-owned orphanage centers performed poorly in care practices compared to Faith-Based Organizations (Makuu, 2017).

\section{Psychological Factors Affecting Orphaned Children}

Orphaned children residing in the institutions suffer from different psychological challenges such as segregation, stigma, isolation, physical punishment, poor attachment and lack of affection (Vedasto, 2015). For instance, the institutionalized orphaned children's care in Zanzibar was inadequate because of its failure to sustain social and psychological needs to orphaned children. Such stance was due to lack of affection, attention, social networks and security (Juma, 2008). UNICEF (2006) found that most of psychological challenges facing orphaned children in the institutions resulted from limited funds, institutional environment and ineffectiveness of caregivers in handling the psychological emotions of orphaned children.

Depression is another challenge that faces the orphaned children when at the centers. According to Masmas et al. (2012) depression is a deep sadness with long-time harmful effects on health and development of the individual. For instance, when parents die, children not only miss their physical presence but also many positive things they gave them when they were alive such as love, care and protection. In many instances, orphans and vulnerable children have no one to share the grief with and this can compound their sense of helplessness. The lack of support during the grieving process and inadequate help in adjusting to an environment without their parents may lead to children to become depressed.

Severely distressed children may suffer in many ways; they may be very lonely, suffer from the loss of their parents, worried about being separated from their siblings, they may find themselves in a situation where they will be abused and neglected, hungry and ill. They may also grieve for long periods over opportunities. Moreover, they may not have someone who gives love and comfort or talk and listen to their needs and concerns (Humuliza, 1999).

According to Erango and Ayka (2015), there is a likelihood of orphaned children being affected by high level of low self-esteem. This is due to lack of social and psychological support, poor parents' social life and death of parents. Psychological care such as provision of good guidance and counseling, physical protection and mutual love are key factors in determining self-esteem. There are other factors that determine the self-esteem of orphans; these are financial and material support and fellowship with other children. When parents live together before their death and reveal strong relationship while having considerable monthly income, the risk of being low in self-esteem will be decreased.

\section{Factors Affecting Caregivers}

President's Emergence Plan for AIDS Relief (President's Emergency plan for AIDS Relief, 2012) reported that death of parents is a traumatic event to children, a tragedy that leaves majority of orphans under severe depression, fear, worries and anger. In due regard, trained caregivers are required to heal down wounds of children in absence of their biological parents. The statistics show that about 80 percent of orphans in Sub Saharan Africa are cared for by caregivers who are too old and majority being older women who also need care as well as comfort from their grandchildren and other society members (Regional Psychosocial Support Initiative (REPSSI) 2011).

It was further observed that challenges facing caregivers in provision of services to the orphaned children in the studied institutions were quite different from those faced by the community. For instance, Vedasto (2015) found out that support to the orphaned children in the caregiver institutions experienced water shortage, inadequate modern cooking fuel, low payments and lack of time for leave. He argued that shortage of funds was the major limiting factor for inadequate payments of caregivers. The institutions depended on temporary donors in paying caregivers' salaries.

A research conducted by Bettmann, Mortensen and Akuoko (2015) in Ghana on institutional care in Ghana, specifically looking at the perceptions of the orphanage caregivers on children's emotional needs, observed that orphans' institutionalized center caregivers faced challenges when children went for the first time in the institutions. Children cried a lot and also they became uncomfortable in 
the new environment and that aspect made the work to be tough for caregivers. Therefore, caregivers needed to be kin and careful in establishing a solid bond with them as much as possible. They further found that the caregivers understood the basic functions in taking care for the orphans at the orphanage centers, especially emotional and interpersonal needs. The study also revealed that the caregivers lacked training and support which were necessary for them to take care of the orphans especially attending the emotional and interpersonal needs to ensure attachment.

\section{Research Methodology}

The study was conducted at six institutionalized centers in Ubungo Municipality. It is one of the six Municipalities that constitute the city of Dar es Salaam. The area was chosen because it has many orphaned centers. According to the 2012 population census, the Municipality had a population of 845,368 where males were 409,149 while females were 436,219. The study had a sample of 67 participants who were selected through purposive sampling technique. They included twelve caregivers, six Directors, one Social Welfare Officer and 48 children. Descriptive research design was used in the study because it accurately and systematically describes situation or phenomenon. Data were collected through in-depth interview and non-participant observation. They were sorted and coded based on themes and presented according to the research questions. Thematic analysis was used in qualitative data. Thematic analysis is the analysis that looks across all data to identify common issues that recur, and identify the main themes that summarize all collected views from the study (Bricki and Green, 2007). This analysis allowed the researchers to put together meanings from statements of the informants within their particular perspective as presented by Joffe and Yardley (2004). One advantage of thematic analysis is that it provides more outcomes when analyzing interviews. This is because it is a flexible tool (Mohamed \& Rajab, 2016). Qualitative method was employed in the study because it provides a much more flexible approach and makes sense of reality. Kothari (2004) maintains that qualitative approach puts emphasis on the qualities, process, and meaning that cannot be experimentally examined.

\section{Validity}

According to Saunde, Thornhill and Lewis (2009) validity refers to the extent to which the measuring questions actually measure the presence of those constructs that intended to be measured. To ensure validity, the researchers designed the research tools i.e. in-depth interview guides and observation schedule in line with the research objective. The researchers conducted a pre-test to the colleagues through interviews. The pre-test enabled the researchers to eliminate the ambiguities and questions that were not clear to the participants. Pilot study was done to one of the institutionalized centers where six orphaned children, one director and one caregiver were involved. The pilot study helped the researchers to validate the instruments. For instance, Kombo and Tromp (2006) argued that data collection instruments, after designing, it is very important for the researcher to test on a small sample of population in order to address clearness of words, researcher's bias, participants' responses and ascertain if the instruments can provide suitable information.

\section{Reliability}

Reliability is the extent to which the variables or set of variables is consistent in what is intended to measure (Saunders at al., 2009). It has to do with extent to which a measurement of a phenomenon provides stable and consistent results (Bricki and Green, 2007). It is basically concerned with repeatability. Data reliability in this study was ensured by comparing the data obtained with those obtained during the pilot study. For instance, two sources in the study gave similar information which suggests acceptable reliability.

\section{Ethical Considerations}

The researchers followed the research clearance procedures and secured a research permit from the Directorate of Postgraduate Studies and Research at Kampala International University in Uganda. The researchers also got an approval letter to conduct the study from the Regional and District administrative bodies. Coughlan, Ryan, F. and Croni (2007) assert that before going to the study area, the researcher must get approval so as to conduct the research. For ethical considerations, names of the respondents and centres studied are not mentioned in this study. Moreover, participants were assured that information they had to provide would be confidential and would be used for academic purposes only.

\section{Results and Discussion}

The study investigated on psychological challenges facing orphaned children and caregivers in the 
institutionalized institutions. The study had three questions. Data were collected through in-depth interview and non-participant observation. Findings are presented according to research questions as follows:

Research Question 1: What are the psychological challenges facing orphaned children in the orphanage institutionalized centers?

Data for this question were collected through interview from the orphan children and caregivers. Results showed that there were various psychological factors that affected the children wellbeing. For example stigma and discrimination were among the identified factors. Here is what one of the boys said: "Children who are grownup call us by names and remind us of our painful memories. For instance, I recall one of them addressing me as an orphan, whose father and mother passed away. That is rude. I don't like it." Another boy added:

When we play football, older boys do not stay out of the playground. They call us bad names. They said that we are ignorant and we do not know how to play football.

One of the girls said: "I am fat. My fellow girls do not like me. They said that I am fat like a pig. This pains me a lot because I do not want to be like I am. They isolate me."

From the findings, one can note that some of the children were not living happily with their peers at the centers. They were faced with stigma and discrimination. Stigma and discrimination affect the psychosocial well-being of the orphans. The fact that children come from different families, different cultural backgrounds and different life styles might have contributed to the problem. They need a careful style of bringing them up that would enable them to love each other and treat each other in a brotherly and sisterly way. At the institutions where children are supposed to respect one another, the caregivers have an important role to educate them about good relationship. Results in this study are similar to those of Makuu (2019) that orphan and vulnerable children are pushed into critical discrimination, stigmatization, abuse and general neglects. allow us to play with them. They tell us to

hand older girls bullied their fellow young girls. Here is what one of the boys said: "Older boys harass me because I am too young to defend myself. They punish me for little mistakes. It is so painful, and it makes me angry such that sometimes I cry." Another boy added: "Older boys forced me to wash their plates because I am not older like them. They told me not to say this to the caregivers. I don't like this but I do not have an alternative way." Another boy claimed: "There are troublesome boys here. They force younger ones to perform their tasks such as washing clothes, cleaning rooms and gardening. They do this in such a way that our caregivers do not see them."

One of the caregivers added: "we have boys who are very rude and troublesome. They force young girls and boys to perform their duties such as washing, cleaning and gardening. Sometimes they use rude and hash language." One of the girls established that: "Older girls force us to wash their plates after eating. When we reject they pinch us. It is painful because we cannot revenge. We are afraid to report to the caregivers because they will beat us more."

Results from the study indicate that bullying was found more serious among the boys than girls. In reality, bullying affects children psychologically. The aim of admitting orphans in the centers is not for children to be bullied by others, but rather to live together while supporting each other socially and psychologically. The fact that children of different ages see bullying or teasing differently, there is a need to prevent such incidents.

Physical punishment was another factor found at the centers. Findings from the study showed that orphaned children experienced physical punishment from their caregivers when they made mistakes. This was done when they committed mistakes like bullying one another, disobedience, delaying to perform given assignments and getting back late from school. Results indicate that corporal punishment was the most used with comparison to other punishments like cleaning the environment. For instance, one of the boys said: "I was caned by a caregiver when I was late from school and when I bullied others. I was also caned for neglecting farm work. I don't like farming." A girl child said: "I was canned by the caregiver when I stole food from the kitchen. I was very hungry and I did not have an alternative. The caregiver called me a thief. I was very ashamed in front of others." Another girl added: "I was pinched by my caregiver because I did not clean up our room. She told me that I am lazy and she did not like me. It pained me a lot. I cried

Furthermore, bullying was found in two orphanages andput nobody cared for me." it was between boys and boys on one hand; on the other 
Physical punishment was used by caregivers as a method of inhibiting undesirable behaviors such as coming late from school, stealing, bullying, late accomplishment of assignments and fighting among orphaned children. During interviews, one of the caregivers from one of the centers refused to admit that children were physically punished. To some extent, physical punishment results to psychological challenges like sadness, anxiety, anger, burnout, isolation, depression, grief, and trauma. Results are similar to those of Albert and John (2017) that orphaned children in the institutions experienced psychological problems through physical punishment, segregation, stigmatization, bullying behaviors and isolation from their fellow children. The challenges were due to lack of affection, attention, social networks and security. These challenges can best be overcome by a psychologist or counselor. Findings also concur with those of Humuliza (1999) that abused and neglected, hungry and ill may grieve for long periods over opportunities. This denotes that institutional centers require caregivers who have counseling and guidance knowledge.

In another development, non-participant observation done by the researchers showed that some of orphan children were not playing with others during day time. The researchers sought to determine the reasons behind. This is what one of the boys said, "I do not want to play. I want to sit alone. I want to go home. I want my mother." This is a sign that the child was poorly attached to his fellows. Human beings do not develop in isolation, but in relation to others in their social environment, in the family, school, community, and society. Results reflect attachment theory that children need to be close to their mothers to improve chances of survival. It is clear that caregivers are given a number of children to take care of but it is not easy for them to pay attention to all children at a time with consideration that they differ in ages, sex and behaviors. At the end this may lead to sadness and stress caused by loss of their biological parents. Results are similar to those of Saraswat and Unisa (2017) that orphaned children felt sad and stressed due to them being in the orphanage center and bereaving for their lost parents. Children showing sadness is an indication that they are yet to overcome the loss and the caregivers have not assisted them. It is now the obligation of the centers to train caregivers and orient them on how to tackle the psychological problems affecting orphaned children for their future psychosocial well-being.

Furthermore, findings from non-participant observation in all six institutions revealed that orphaned children suffered from anxiety and fear. Despite the fact that they were given food and clothes and sport gears they were still not happy. Some of them were found sitting alone. Some were crying. The implication here is that psychological challenges were not addressed accordingly. From Bowlby's attachment theory feeding does not diminish the anxiety experienced by children when they were separated from their primary caregivers. This might be due to lack of knowledge and skills to handle psychological challenges facing the children. The present study result supports those of Murray et al. (2015) who found that orphan children experience more anxiety, depression and trauma than non-orphan children. This may be due to lack of true love, which could be revealed from the biological parents.

Research Question 2: What are the challenges facing caregivers in the orphanage institutionalized centers?

Findings from all institutionalized centers exposed that caregivers were faced with various challenges. Most of the challenges originated from the children. For example, there were children who demonstrated bad behaviors like use of abusive language, fighting and disobedience. Here is what a caregivers said: "It is not easy to discipline all children at a time because they behave differently. The more serious I become in disciplining them, the more they hate me. So, it is not an easy task to take care of a child who is not yours." Another Caregiver had this to say:

I tried to discipline two boys who were troublesome but they rejected. They decided to leave the center without permission. I do not know where they are now. In fact I am not happy on what happened. I feel like I am not capable enough to do this work.

One more caregiver added:

This job is very challenging especially to those children who were taken from the streets. They are too difficult to be controlled or disciplined. They don't like to stay here. They want to go back to the streets in order 
to be free. For them to do small chores is like punishment.

From the findings one can find that caregivers had problems in coping with situations. It was a serious challenge to them. However, some of the caregivers tried their best to handle them. Others who found the work difficult gave up. For example, the interview with a social welfare showed that working environment was not friendly to some of the caregivers. She said that one of the caregivers stopped working at the center because she was abused by the director in front of her fellow workers and the reason being she had punished one of the children who abused her. The caregiver had no choice rather than punishing the child in order to stop the bad behavior. She thought what she did was right but instead she was reprimanded by the director. So, she decided to leave the center. The findings are similar to those of Kaur and Colleagues (2018) who found behavioral problems prevailing in the orphanage centers in India. That challenge indicated that caregivers were not trained in the field of parenting, psychology and counseling, which could have helped them in handling children with different personalities.

\section{Conclusions and Recommendations}

This section presents the conclusions of the study and then comes up with the recommendations of the study.

\section{Conclusions}

The study concludes that orphan children experience psychological challenges such as depression, stress, stigma, physical punishment, bullying behavior, anxiety, sadness, anger and isolation. These factors collectively affect the overall well-being of orphaned children. Provisions of food, clothes and sport gear without guidance and counseling, love and protection from caregivers will not solve orphans psychological problems at the centres. The central theme of Bowlby's attachment theory is that primary caregivers who are available and responsive to an infant's needs should allow the child to develop a sense of security.

\section{Recommendations}

The researchers came up with a number of recommendations: firstly, to educate the society/community on the importance of supporting orphans in terms of capital. Support does not only mean food, clothes and money but visiting them at the centers will inculcate in them a sense of humor, love and care.

Secondly, the centers need to improve counseling services to the orphans and to educate them on self-awareness. All this will best be achieved if each center would have a counselor. The care givers should be trained on best practices to handle the orphans. Moreover, there should be improvement on recreational services for the children, including social activities, which mostly put orphans together rather than letting them be isolated. This will improve the emotional support to orphans. Such measures will strengthen the role of caregivers and develop the social network with the community.

Thirdly, institutional centers should employ caregivers who are trained on psychology, passion to children so that they can be attentive to orphans issues. Institutional centers need to have counseling sessions. Such measures will provide a remedy to children's psychological problems. Also, the community has an important role to play in building up the psychosocial well-being, especially through respecting the orphans, helping them and caring as well as supporting them. According to Saraswat and Unisa (2012), most of the orphans in the institutionalized children's centers face one or more psychological problems. Therefore, the quality of care given to orphans can determine their psychological well-being. Additionally, the government, stakeholders and communities should play the role of ensuring that orphaned children are provided with social services and psychological support as well as counseling training for caregivers in order to minimize children's psychological complexities.

\section{References}

African Charter (1990). Rights and welfare of the child. AU: Addis Ababa.

Atwine, B., Cantor-Graae, F. and Bajunirine, F. (2005). Psychological distress among AIDS orphans in rural Uganda. Journal of Social Science and Medicine, 61(3), 555-564.

Albert, M. \& John, M. (2017). Psychological challenges affecting primary school going orphans in Wanganuii Community, Zimbabwe. International Journal of Scientific and Technology Research, 6( 4), 193-201.

Bettmann, J. E., Mortensen, J. M., \& Akuoko, K. O. (2015). Orphanage caregivers' perceptions 
of children's emotional needs. Children and Youth Services Review, 49, 71-79.

Bowlby, J. (1969). Attachment and loss: Attachment Vol. 1. ( $2^{\text {nd }}$ edn). New York: Basic.

Bricki, N., \& Green, J. (2007). A guide to using qualitative research methodology. http://hdl.handle.net/10144/84230.

Brizay, U. (2008). Best practice guide for comprehensive orphan care in Tanzania. Germany: Block-Verg Publishers.

Caserta, T. A. (2017). The psychological well-being of orphans and youth in Rwanda: Analysis of predictors, vulnerability factors and buffers. Publications of the Department of Social Science, Social Psychology: University of Helsinki.

Christian Alliance for Orphans (2014). Global orphans facts. http://www.christianalliance fororphans.org/resources/orphans-fact.

Coughlan, M., Ryan, F, \& Croni, P. (2007). Step-bystep guide to critiquing research. Part 2: Qualitative research. British Journal of Nursing.https://scholar.google.com

Daniel, M. \& Rukundo, P. (2016). Children orphaned by AIDS in Uganda: Can they thrive under orphanage care? Social Work and Society International Online Journal , 14(1).

Davids, A., Nkomo, N., Mfecane, S., Skinner. D. \& Ratele, K. (2006). Translating research into policy: The case of orphans and vulnerable children in South Africa. Journal of Social Aspects of HIV/AIDS, 43(5), 865-872.

Erango, M. A. \& Ayka, Z. A. (2015). Psychosocial support and parents' social life determine the self-esteem of orphan children. Risk Manag Healthc Policy. (8), 169-173.

Humuliza, (1999). Manual: Psychosocial support of children affected by AIDS: Terre des Homes, Switzerland Based/Nshamba.

Huynh, H. V., Limber, S. P., Gray, C. L., Thompson, M. P., Wasonga, A. I., \& Vann, V. (2019). Factors affecting the psychosocial wellbeing of orphan and separated children in five low- and middle-income countries: Which is more important, quality of care or care setting? Public Library of Science ONE 14(6): e0218100. https://doi.or g/10.1 371/ journal.pone.
Ismail, L. B., Hindawi, H., Awamleh, W., \& Alawamleh, M. (2018). The key to successful management of child care centres in Jordan. International Journal of Child Care and Education Policy, 12(1), 1-19.

Ismail, A. (2020). The increase of street children in Tanzania Mainland: What can be done to combat and prevent the problem? Master of Arts (Applied Social Psychology) Unpublished Thesis. University of Mzumbe, Morogoro, Tanzania.

Joffe, H. \& Yardley, L., (2004). Content and thematic analysis: Research methods for clinical and health psychology. California: Sage Publications.

Juma, S. K. (2008). Social and psychological problems facing orphaned children in Zanzibar. Papers in Education and Development, Vol. 28, 139-160.

Kaur, R., Vinnakota, A., Panigrahi, S., \& Manasa, R. V. (2018). A descriptive study on behavioral and emotional problems in orphans and other vulnerable children staying in institutional homes. Indian Journal of Psychological Medicine, 40(2), 161-168.

Kombo, K. D. and Tromp, L. A. D. (2006). Proposal and thesis writing: An introduction. Nairobi: Pauline Publications Africa.

Kothari, C.R. (2004). Research methodology. New Delhi: New Age.

Losioki, B. E. (2020). Education opportunities and support for orphans and vulnerable children in Bagamoyo District. East African Journal of Education Studies 2(1), 187-197.

Majaliwa, K. (2020). Tanzania has over 24,000 children living in orphanages says PM. The Citizen, https://www.thecitizen .co.tz/ tanz ania/news/tanzania-has-over-24-000-childr en-living-in-orphanages-says-pm-2682754.

Makuu, M. J. (2017). Family matters: Strengthening alternative care systems for orphans and vulnerable children in Dar es Salaam, Tanzania. PhD (Social Work) Unpublished Thesis, University of Botswana, Botswana.

Makuu, M. J. (2019). Situation analysis of orphans and vulnerable children in existing alternative care systems in Dar es Salaam, Tanzania. Social Work \& Society, 17(1), 1-17. 
Masmas, T. N., Jansen, H., Da Silva, D., Høj, L., Sandström, A. \& Aaby, P. (2012). Survival among motherless children in rural and urban areas in Guinea Bissau. Journal of Acta Paediatrici, 93(1), 99-105.

Mchau, M. G. (2010). Adequacy of psychosocial care services provided to orphaned children by caregivers in Temeke District, Dar es Salaam Region, Tanzania. Master of Art (Applied Social Psychology) Unpublished Thesis. University of Dar es Salaam, Tanzania.

Mdamu, J. (2017). Sexual and reproductive health among adolescents living in orphanages in Dar es Salaam. Master of Science (Public Health) Unpublished Thesis, Muhimbili University of Health and Allied Sciences, Tanzania.

Mears, M., Singletary, J. \& Rogers, R. (2011). Strategies for supporting orphans and vulnerable children: An explanatory study of an exemplary model of care in Kenya. Child and Youth Services, (32), 286-302.

Ministry of Health and Social Welfare (2009). National guidelines for improving quality of care, support and protection for most vulnerable children in Tanzania. http://www.africanchildforum.org/clr/polic y\%20per\%20country/tanzania/tanzania_ser viceguideline_2009_en.pdf.

Mohamed, M., \& Rajab, M. (2016). Qualitative analysis methods and review. College of Business: Technological University Dublin.

Msoka, A. \& Holroyd, E. (2018). Children's perspectives of their psychosocial wellbeing in Tanzanian orphanages. International Journal of Nursing and Midwifery, 10(5), 4146.

Murray, L. K., Skavenski, S., Kane, J. C., Mayeya, J., Dorsey, S., Cohen, J. A. \& Bolton, P. A. (2015). Effectiveness of trauma-focused cognitive behavioral therapy among traumaaffected children in Lusaka, Zambia: A randomized clinical trial. JAMA Pediatrics, 169(8), 761-769.

Ntuli, B., Mokgatle, M., \& Madiba, S. (2020). The psychosocial wellbeing of orphans: The case of early school leavers in socially depressed environment in Mpumalanga Province, South Africa. Plos one, 15(2).
Pillay, J. (2016). Factors leading to orphans and vulnerable children living in communitybased homes. Journal of Psychology in Africa, 26(6), 558-561.

President's Emergency plan for AIDS Relief (PEPFAR) (2012). Guidance for orphans and vulnerable children programming www.pepf ar.gov/docu ments/organiza tion/19 5702. pdf

Report on World's Orphan (2014). Human and Social Researches Center: Istanbul,Turkey.

REPSSI (2011). Psychosocial care and support for older careers of orphaned and vulnerable children: Policy guidelines. Nairobi: Help Age International.

Saraswat, A. \& Unisa, S. (2017). An in-depth study of psychosocial distress among orphan and vulnerable children living in institutional care in New Delhi, India. Journal of Health and Social Sciences, pp. 195-208.

Saunders, M., Thornhill, A. \& Lewis, P. (2009). Understanding research philosophies and approaches. Research Methods for Business Students, Vol. 4.https://www.researchgate .net/publication/309102603.

Save the Children (2013). Save the children's child protection strategy 2013-2015. Kingdom: Save the Children.

Sharif, F. \& Haider, SI. (2020). Anxiety, depression: Stress and decision-making among orphans and non-orphans in Pakistan. http://doi.org /10.2147/PRBM.S245154.

World Bank. (2018). Poverty and shared prosperity 2018: Piecing together the poverty puzzle.https://elibrary.worldbank.org/doi/a bs/10.1596/978-1-4648-1330-6.

UNAIDS (2010). Global report on the global AIDS pandemic. New York: JUNP on HIV/AIDS.

UNICEF (1997). Children at risk in Central and Eastern Europe: Perils and promises. International Child Development Centre: https://scholar. google.com.

UNICEF (2006). Care for children affected by HIV and AIDS. Innocent Research Centre: Florence, Italy.

UNICEF (2008). The state of the world's children 2008: Child survival Vol. 8. 
UNICEF (2012). Cities and children: The challenges of urbanization in Tanzania, Dar es Salaam, Author.

UNICEF (2018). Annual Report 2018: For Every Child, Every Right. https://www.unicef.or g/repor ts/annual-report-2018.

UNICEF (2020). Humanitarian Action for Children 2020: Overview. https://scholar.googl e.com/schol ar?hl=en\&as_sdt=0\%2C5\&q $=+$ Humanitarian+Action+for+Children+2020 +Overview+Children+and+young+people +af fected+by+crises+call+for+concrete+ac tion +to+ protect+and+promote+their+righ ts+\& btnG=

UNICEF (2015). Thousands of children orphaned by Ebola. https://www.unicef.org/media/me dia_76085.html.

Vedasto, V. (2015). The effectiveness of caregivers' psychosocial service provision to orphaned children: A case study of orphanages in Kinondoni Municipality. Master of Arts (Applied Social Psychology) Unpublished Thesis, University of Dar es Salaam, Tanzania. 